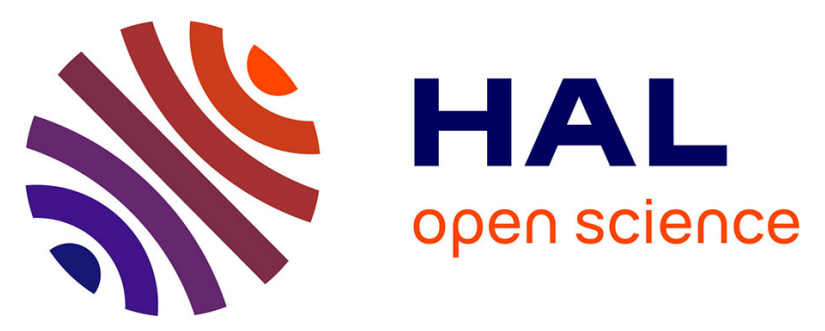

\title{
Assessing the relationship between pest density and plant damage: a case study with the belowground herbivore Delia radicum (Diptera: Anthomyiidae) on broccoli
}

Xavier Mesmin, Marie Vincent, Yann Tricault, Vianney Estorgues, Loïc

Daniel, Anne-Marie Cortesero, Vincent Faloya, Anne Le Ralec

\section{To cite this version:}

Xavier Mesmin, Marie Vincent, Yann Tricault, Vianney Estorgues, Loïc Daniel, et al.. Assessing the relationship between pest density and plant damage: a case study with the belowground herbivore Delia radicum (Diptera: Anthomyiidae) on broccoli. Applied Entomology and Zoology, 2019, 54 (2), pp.155-165. 10.1007/s13355-019-00607-3 . hal-02063365

\section{HAL Id: hal-02063365}

\section{https://institut-agro-rennes-angers.hal.science/hal-02063365}

Submitted on 22 Mar 2019

HAL is a multi-disciplinary open access archive for the deposit and dissemination of scientific research documents, whether they are published or not. The documents may come from teaching and research institutions in France or abroad, or from public or private research centers.
L'archive ouverte pluridisciplinaire HAL, est destinée au dépôt et à la diffusion de documents scientifiques de niveau recherche, publiés ou non, émanant des établissements d'enseignement et de recherche français ou étrangers, des laboratoires publics ou privés. 
1 Assessing the relationship between pest density and plant damage: a case study with 2 the belowground herbivore Delia radicum (Diptera: Anthomyiidae) on broccoli

Xavier Mesmin ${ }^{\text {a }}$, Marie Vincent ${ }^{a}$, Yann Tricault ${ }^{b}$, Vianney Estorgues ${ }^{c}$, Loïc Daniel ${ }^{\mathrm{d}}$, AnneMarie Cortesero ${ }^{\text {a }}$, Vincent Faloya ${ }^{d}$, Anne Le Ralec ${ }^{\text {a }}$

${ }^{a}$ IGEPP, Agrocampus Ouest, INRA, Université de Rennes 1, Université Bretagne-Loire, 35000 Rennes, France

${ }^{b}$ IGEPP, Agrocampus Ouest, INRA, Université de Rennes 1, Université Bretagne-Loire, 49000 Angers, France

${ }^{c}$ Chambre régionale d'agriculture de Bretagne, Kergompez, 29250 Saint-Pol-de-Léon, France

${ }^{d}$ IGEPP, Agrocampus Ouest, INRA, Université de Rennes 1, 35650 Le Rheu, France

\section{Abstract}

For many crops, we have poor knowledge about the relationship between pest density and damage. However, investigating pest harmfulness is particularly relevant currently in the search for alternative crop protection strategies that are unlikely to totally suppress pest populations. Here, we assessed the harmfulness of Delia radicum (L.) on broccoli (Brassica oleracea var. italica Plenck). We worked inside insect-proof cages set up in the field with additional pitfall traps to remove ground dwelling predators. Plants were manually infested with 10 levels of pest density ranging from 0 to 100 individuals per plant, following a natural infestation pattern. Surprisingly, no plants died but almost $100 \%$ of the pests introduced died over the course of the experiment. However, all broccoli development and growth traits were negatively correlated with pest density and broccoli head mass at harvest decreased linearly with pest density. The observation over time of development and growth traits showed evidence of plant compensation, suggesting that the head mass of individual plants may have reached similar values if allowed to fully mature. The relationship between pest density and damage, together with forecast models of pest population dynamics could be used to develop decision support tools assessing the relevance of preventative treatments.

\section{Keywords}

Crop losses; plant traits; plant injury; damage; plant compensation.

\section{Introduction}

Throughout the history of agriculture, the development of pest management strategies has led to dramatic decreases in crop losses to pests (Oerke 2006). However, the predominant crop protection method, that is pesticide usage, has various negative consequences, notably on human health and the beneficial fauna of agro-ecosystems (Desneux et al. 2007; Geiger et al. 2010). Alternatives are therefore urgently needed, but in contrast to pesticides, most of these alternatives (push-pull, insect netting, intercropping...) are likely to have partial efficiency. For example, conservation biological control, based on the enhancement of natural enemy populations, is thought to be an interesting method for reducing crop losses (Eilenberg et al. 2001) but is incompatible with the complete suppression of pest populations because by 
definition, predators cannot maintain their populations without prey. It is therefore necessary to reconsider the relationship between pest density, plant injuries (i.e. the symptoms of pest development on the physiology of the host; Pedigo et al. 1986) and damage (i.e. the decrease in yield quantity or quality; Zadoks 1985; Pedigo et al. 1986). In this context, pest populations should reach an intermediate size that is both $\mathrm{i} /$ high enough to allow the build up of efficient natural enemy communities, including several specialists depending on this specific resource (Devictor et al. 2010) and ii/ low enough to result in acceptable losses for the farmer, a level that is likely to depend on the production situation (sensu Aubertot and Robin 2013) (International Conference on Global Crop Losses 2017). In many cases, plants are able to tolerate moderate levels of pest infestation (Poston et al. 1983; Fenemore 1984; Pedigo et al. 1986), i.e. to withstand injuries without significant damage (Verdugo et al. 2016), so that this intermediate pest population size could be innocuous in several pest/crop systems (e.g. Rogers and Brier 2010).

In general, injuries and damage due to below ground pests have been less well studied than those inflicted by above ground pests (Hunter 2001). This may be due to methodological constraints because recording freshly caused injuries below ground necessarily involves destructive sampling, thus preventing the evaluation of subsequent damage. However, the effects of pest development below ground are not restricted to root tissue loss and indirect effects of root injuries could also occur above ground (Teixeira et al. 1996; Murray et al. 1996; Hunter 2001). Indeed, the physiological and morphological consequences of root injuries can include reduced leaf surface (Cardona et al. 1982), plant height and above ground biomass (Boica Junior et al. 2015), as well as an increase in lignin content (Hopkins et al. 1995), and soluble nitrogen concentration in the sap (Gange and Brown 1989). Gange and Brown (1989) suggested that due to root removal, below ground pests could have a similar effect as drought on plants. These indirect effects which can be assessed by monitoring plant growth and development above ground, may or may not lead to a significant decrease in final yield (Rosenheim et al. 1997; Brandelero et al. 2016).

Delia radicum (L.) (Diptera: Anthomyiidae) is the main pest of Brassica vegetables in northwestern Europe. The main cause of damage due to this pest in leaf and flower vegetables is early plant mortality, which can reach 40-60\% without insecticides (Estorgues 2005). Females lay their eggs on the ground, within a distance of $5 \mathrm{~cm}$ from plant stems (Hughes and Salter 1959). The larvae then develop by feeding on plant roots throughout three life stages. They thereby inflict injuries to the roots with several potential consequences on the plants (see above) among which the disturbance of water and nutrient uptake (Gange and Brown 1989). Several studies have been performed to quantify the damage inflicted by this pest on two Brassica crops: cauliflower and oilseed rape. Turnock et al. (1992) did not find a relationship between injuries caused by root maggots and yield of oilseed rape, hence suggesting that cropped plants fully compensated for injuries, at least up to the maximal tested pest density (25 eggs per plant). In cauliflower, El Titi (1979) showed a correlation between egg density and plant mortality for infestation levels ranging from 10 to 60 eggs per plant. This study was used by Bligaard et al. (1999) to define an economic threshold of D. radicum on cauliflower, suggesting that intervention was needed if more than one egg was found per felt trap (used for monitoring egg laying) and per day two to four weeks after planting. This threshold is still used by farmers and advisors in France to evaluate the intensity of pest infestation, but it is no longer 
relevant in terms of decision making because: $i /$ the chlorfenvinphos used by El Titi (1979) is now prohibited and ii/ the current protection strategy against the cabbage root fly is preventative and consists of drenching the roots of all leaf and flower Brassica vegetables with spinosad (Success $^{\text {TM }}$ 4) before planting. Also in cauliflower, Bligaard (1999) performed several experiments with varying times of infestation and found that plant biomass decreased when egg density rose from 0 to 25 eggs per plant, but final yield was not monitored. Only one study showed reduced production of surviving cauliflowers in response to D. radicum attack (El Titi 1977). Finally, a methodological limitation in these previous studies was that the eggs were always introduced all at once. This pattern is unrealistic compared to natural infestation (Estorgues 2005) and may have had consequences on pest survival, plant-pest interactions and therefore on the subsequent damage: Finch and Skinner (1988) showed increased D. radicum survival for instant egg inoculation compared to protracted inoculation.

The objective of the present study was to assess D. radicum harmfulness on broccoli Brassica oleracea var. italica Plenck (Brassicales: Brassicaceae), a crop for which we expected a similar tolerance as that previously observed for cauliflower. For this, we worked on caged plants grown in the field to ensure natural root development and we controlled pest density using artificial egg infestations. We expected broccoli to show a tolerant response to D. radicum (Poston et al. 1983), with compensation for low injury levels, hence no damage; and damage resulting from greater levels of injury, ranging from yield reduction to plant mortality.

\section{Materials and methods}

\section{Study site and experimental design}

The experiment was conducted in an $850 \mathrm{~m}^{2}$ plot at INRA's experimental station (UE0787, Domaine expérimental de la Motte au Vicomte), in Le Rheu, France (48 $06^{\prime} \mathrm{N}$; $\left.1^{\circ} 47^{\prime} \mathrm{W}\right)$ during spring 2016 . The field used for this study has a deep soil $(80-120 \mathrm{~cm})$, hydromorphic from the surface, originating from shale and wind deposited loam (classified as luvisol following the international soil classification system of the IUSS Working group WRB 2015). Previous crops were maize in 2012, 2013, 2014; fava beans in 2015 and meadow for seven months before this study started. Six insect-proof cages $(6 \mathrm{~m}$ long $\times 3 \mathrm{~m}$ wide $\times 2 \mathrm{~m}$ high; $300 * 300 \mu \mathrm{m}$ mesh; Diatex $®)$ were set up on the plot. On the $5^{\text {th }}$ of April 2016, 30 untreated broccoli plants (cv. 'Marathon') at the stage of two true leaves were planted in each cage, every $0.50 \mathrm{~m}$ in rows $0.75 \mathrm{~m}$ apart. Insect-proof cages prevented plant colonization by flying insects, whether they were females from surrounding cabbage root fly populations, other Brassica pests or D. radicum natural enemies. PET barriers (Greenborder, Nortene $\left.{ }^{\circledR}\right)$ buried all around the cages (60 $\mathrm{cm}$ high, 40 of which below ground) prevented hypogeic and epigeic organisms from gaining access. Two sticky panels $(29.7 * 42 \mathrm{~cm})$, a yellow and a blue one, were hanged inside each cage in order to catch flying arthropods that could emerge from the soil. Twenty four pitfall traps were also set up in each cage (i.e. 1.3 per $\mathrm{m}^{2}$ ) to reduce predation by ground dwelling arthropods on immature fly stages. Pitfall traps were half-filled with water and a few drops of odorless detergent. Barriers and traps were set up 13 days before planting, and the cages, the day before planting. 
Eggs were manually deposited on plants inside insect-proof cages. The timing of egg additions was designed to mimic the natural egg laying dynamics of $D$. radicum, which is generally centered on a peak that represents about $40 \%$ of the total amount laid (calculation based on previous experiments performed under natural infestation conditions). The first natural egg laying peak is quite stable over the years in north-western France and typically occurs between early and mid-May when transplanting is done at the beginning of April (Estorgues 2005). We hence spread the infestation out over three consecutive weeks with a peak on the $2^{\text {nd }}$ of May representing $40 \%$ of the total amount of eggs applied on each plant. The two other inputs were made on the $25^{\text {th }}$ of April and on the $9^{\text {th }}$ of May, each representing $30 \%$ of the total amount of eggs applied per plant. We defined ten pest densities, summarized in Table 1, ranging from 0 (control) to 100 eggs per plant, a range similar to egg counts made in production fields from the same region (Josso et al. 2013).

The eggs were obtained in the laboratory from a strain of $D$. radicum originally collected in fields of the same experimental station in early summer 2015 and reared as described in Lamy et al. (2017). Females were offered slices of swede placed on a filter paper for egg laying. The eggs were then brought to the field and directly used for infesting the plants. They were deposited at the base of plant stalks with a fine paintbrush. At each date of plant infestation, an additional batch of about 300 eggs was placed in a Petri dish, on a moistened filter paper and kept in a climate-controlled room $\left(16: 8 \mathrm{~h}\right.$ photoperiod and $\left.20^{\circ} \mathrm{C}\right)$. After seven days, natural egg mortality was estimated as the proportion of unhatched (i.e. dead) eggs. Infestation levels were distributed to broccoli plants in a randomized complete block design: inside each cage, egg density was attributed randomly to each plant; there were three broccoli plants for each egg density in each cage, thus a total of 18 plants per egg density in the experiment.

At broccoli harvest, i.e. on June 21 and 22, a soil sample $(12 \mathrm{~cm}$ in diameter and $13.5 \pm$

\section{Plant development and growth} $0.4 \mathrm{~cm}$ (mean $\pm \mathrm{SE}$ ) in depth, ensuring the collection of more than $70 \%$ of the pupae; Hughes 1960; Finch et al. 1978) was taken around each broccoli root with a motorized auger. The number of $D$. radicum larvae and pupae was counted after washing the samples through a $1 \mathrm{~mm}$ * $1 \mathrm{~mm}$ mesh sieve.

We evaluated plant development and plant growth weekly for every broccoli plant from April 12 to June 14 (i.e. during 10 weeks). The development of each plant was assessed by recording the leaf numbers, the presence / absence of at least one lateral sprout and the presence / absence of a visible inflorescence. These measurements match the three main stages of broccoli development (Feller et al. 1995). Plant mortality was also recorded. Plant growth was evaluated via two measurements: the product of the largest leaf length and width (thereafter called "relative leaf area"), known to be highly correlated with leaf area in Brassica crops (Olfati et al. 2010; Cargnelutti Filho et al. 2015; Tartaglia et al. 2016) and the height above ground of the apical meristem (thereafter simply called "plant height" in the text), often used to give complementary information on plant growth (Kloen and Altieri 1990; Brandelero et al. 2016). 
As the first broccoli had reached their optimal development regarding marketable standards (buds tight and close to opening), we harvested every plant in a row on the $21^{\text {st }}$ and $22^{\text {nd }}$ of June. Stalks were cut about $1 \mathrm{~cm}$ below the insertion of the first branch of the head and heads were weighed with a spring scale (precision $= \pm 5 \mathrm{~g}$ ).

Injuries caused by $D$. radicum larvae feeding on plant roots was assessed by visual examination using the scale defined by Dosdall et al. (1994): $0=$ no injury; $1=$ slight feeding, $<10 \%$ of tap root surface injured; 2, 3, 4 and 5 respectively $10-25 \%, 26-50 \%, 51-75 \%, 76-$ $100 \%$ of root surface injured.

\section{Data analysis}

Generalized linear mixed models were used to analyze every dimension of plant development, growth and production. We generated a model for every dimension of plant development (i.e. number of leaves, proportion of plants with at least one lateral shoot and proportion of plants with an inflorescence) and growth (i.e. relative largest leaf area, plant height) including the number of eggs (quantitative), the sampling session (factor), and their interaction as fixed effects as well as the cage and plant identifiers as random effects to account respectively for potential spatial correlation among data obtained inside the same cage and for the fact that the same plants were monitored in each session (Faraway 2006). The analysis of lateral shoots and inflorescences was restricted to the dates when shoots or inflorescences were recorded, respectively. For the latter, only two measurement sessions were analyzable which made it impossible to use the plant identifier as a random factor. This proportion was therefore analyzed at the cage scale and the random effect set for the cage identifier to account for repeated measures (Faraway, 2006). Pearson correlation coefficients were computed among all development and growth traits over their respective period of analysis (Table S1 in Supplementary materials).

The effect of the number of eggs on the proportion of plants displaying root injuries (injury class $>0$ ) and on final head mass was assessed, using a random factor set for the cage identifier to consider potential spatial correlation among data obtained inside the same cage.

All statistical analyses were performed using $\mathrm{R}$ software ( $\mathrm{R}$ core team 2017). The models described above were fitted using generalized linear mixed modeling (functions 'Imer' or 'glmer' of the package 'Ime4'; Bates et al. 2015) with a distribution and link function adapted to the data analyzed: identity-link Gaussian (response variables: log transformed number of leaves; log transformed relative largest leaf area; square root transformed plant height; final head mass) or logit-link binomial (response variables: proportion of plants with at least one lateral shoot; proportion of plants with an inflorescence; proportion of plants with root injuries). When necessary, an additional random factor set for the statistical individual was used to account for data overdispersion. The significance of the fixed effects was tested using type II Wald chi-square tests (function 'Anova', package 'car'; Fox and Weisberg 2011).

Post-hoc tests were performed on the models fitted on plant development and growth traits. We studied the effect of egg density on plant traits as a function of time: for each date 
(factor level), we estimated the marginal slope of the linear trend between egg density and plant traits (in cm/egg for plant height for instance; function 'emtrends' with back-transformation of the slopes to the response scale; package 'emmeans'; Lenth 2017). Then we extracted the slope of the steepest relationship between each plant trait and egg amount. These values provided estimates for the strongest effects of pests on plant traits observed in our experimental design.

Thirty plants (i.e. 17\%) suffered from slug attack or lost their apical meristem so that it

Plant survival and mortality of $\mathrm{D}$. radicum immature stages

The 150 broccoli plants survived the entire experiment. The proportion of unviable eggs among the three batches used for artificial infestations was similar with an overall mean of $18.9 \%( \pm 1.3 \%)$. At the end of the experiment, a total of only two pupae was recovered from the soil samples taken around the plant roots, suggesting a high mortality of the 6065 introduced eggs before reaching their final developmental stage.

\section{Plant development and growth}

The relative largest leaf area, plant height and the number of leaves were highly correlated, with Pearson correlation coefficients exceeding $90 \%$. In contrast, none of the data had a correlation coefficient exceeding $63 \%$ with the proportion of plants with an inflorescence and coefficients did not exceed $37 \%$ for correlations with the proportion of plants with at least one lateral shoot (Table S1 in Supplementary materials).

Except for the proportion of plants with at least one lateral shoot, all development and growth traits were negatively correlated with an increase in pest density (Table 2). The interaction between measurement dates and the number of eggs deposited was significant for growth traits, but not significant for development traits.

Plant trait responses to pest attack followed a similar pattern (Fig. 1) of 1) no preexisting trend in development and growth traits prior to pest input; then 2) a transient negative effect becoming significant after a delay varying from a couple of days to several weeks after the first infestation, depending on the trait, and finally 3) a waning of the effect with no significant trend at the end of the experiment. Hence, even the highly infested plants recovered and showed the same final development and growth states as those of non-infested plants, as measured by our parameters. The exception was plant height, which remained negatively correlated with egg density until the end of the experiment. All plants produced an inflorescence and $73 \%$ produced at least one lateral shoot by the end of the experiment. The time course of negative effects of egg density (Fig. 1) indicates that these organs appeared later when plants suffered high pest densities.

The date at which the most negative trend between egg density and development or growth trait was observed varied depending on the trait considered. It ranged from 23 days to 50 days after the first artificial egg infestation for the proportion of plants with lateral shoots and the plant height respectively (Fig. 1). Focusing on this particular date, the models indicated 
linear relationships between plant traits and egg density (Fig. 2), with only slight deviations from linearity for the proportion of plants with at least one lateral shoot or with an inflorescence, which may simply be due to the binary nature of these response variables.

\section{Root injuries and final head mass}

All plants harvested were in injury class 0 or 1 (i.e. less than $10 \%$ of the tap root surface injured). The proportion of plants with root injuries due to $D$. radicum larvae feeding increased linearly with the number of eggs deposited $\left(\chi^{2}=13.0 ; \mathrm{df}=1 ; \mathrm{P}<0.001 ;\right.$ Fig. 3$)$.

All plants produced a broccoli head, with an overall mean yield of $295.9 \pm 13.8 \mathrm{~g}$ per plant. Plant production was negatively and linearly correlated with the amount of eggs deposited on the plant $\left(\chi^{2}=11.1, \mathrm{df}=1, \mathrm{P}<0.001\right.$; Fig. 3 ). For a rise from 0 to $100 \mathrm{eggs}$, the predicted drop in broccoli mass was $136.1 \mathrm{~g}$, for an attainable mass of $346.8 \mathrm{~g}$, i.e. a loss of $39 \%$ of the attainable mass.

\section{Discussion}

The two main results of this study are that 1) all plant development and growth traits, as well as the final mass of broccoli heads, were negatively correlated, at least transitorily, with D. radicum egg density and 2) no plants died and all produced a harvestable head despite a maximum pest density expected to lead to plant death.

\section{D. radicum affects all development and growth traits and reduces plant production}

All development and growth traits were negatively and linearly correlated with pest density, at least for one measurement date. Additionally, broccoli mass decreased linearly with the amount of eggs deposited, when the first plants were ready for harvest. Our results therefore confirm that development delays and reduced plant growth during the growing season can lead to significant drops in head mass at harvest, at least when all plants are harvested in a row (Brandelero et al. 2016). This result is interesting because plant mortality is currently regarded as the main damage caused by the cabbage root fly on broccoli (El Titi 1979; Estorgues 2005). Similarly, El Titi (1977) found a negative correlation between $D$. radicum pupae density and vegetable mass in cauliflower, suggesting that this type of relationship between pest density and yield might be found for other Brassica crops. Our results indicate that (at least when no plant mortality occurs) the impact of $D$. radicum on plants is linear, with no threshold: even the lowest pest densities limit plant growth and head mass. This is not exactly consistent with the findings of Bligaard (1999), which suggested threshold effects in the relationship between the biomass (a growth trait) of cauliflowers and D. radicum egg density. Our results therefore suggest that $D$. radicum can be harmful even when it does not kill the plants.

However, all development and growth traits, except above ground plant height, were no longer correlated with pest density at the time of the final measurement. Thus it appears that the plants were compensating for the injuries caused by the pest. We therefore suggest that the production potential of each plant, i.e. the attainable yield if every plant had been harvested at individual maturity, may not have been modified by pest density in our experimental conditions, but that the plants had not yet fully compensated for the pest attack by the end of our experiment. The plants may thus have been able to tolerate the pest attacks (Strauss and Agrawal 1999; 
Verdugo et al. 2016), as shown in many non-crop plants (e.g. Heichel and Turner 1983; Fowler and Rausher 1985; Karban and Courtney 1987; Maschinski and Whitham 1989) but also for instance in Aphis gossypii infesting cotton (Rosenheim et al. 1997). In the latter study, comparing infested and non-infested plants, the authors showed that leaf area was transitorily reduced by $58 \%$ when plants were infested with aphids but then by harvest the cotton plants had fully recovered so that yield was not affected (Rosenheim et al. 1997). In our crop/pest system, the consequences of pest infestation in terms of damage are likely to depend on the production situation. If the harvest is spread over several weeks, e.g. in the context of market gardening where produce is harvested only in time for sale, plants may reach their potential and D. radicum infestation may not affect final yield. In contrast, when the aim is to reduce the number of harvests to limit the costs, e.g. in the context of field vegetable production where the volumes are large and the associated costs for harvest are high, D. radicum is likely to add to the natural variability of the time needed to reach plant maturity (Dufault 1997; Grevsen 2000; Lindemann-Zutz et al. 2016). Thus, an infestation may lead to either additional harvests being performed, thereby increasing production costs, or to an increased amount of unharvested plants (because not fully mature at harvest), decreasing the income.

The absence of plant mortality and D. radicum mortality

A surprising result of our experiment is that no plants died. Two hypotheses may explain this: 1) the maximum egg densities were not high enough to kill plants in our growing conditions or 2) the maximum egg densities should have killed the plants but the unexpected high developmental mortality of $D$. radicum led to an underestimation of the real harmfulness of this pest. In previous studies on cauliflower, El Titi (1979) and Bligaard (1999) reported significant plant mortality with much lower egg densities (respectively 60 and 25 eggs per plant), introduced when plants were at a similar developmental stage ( 4 leaves). However, the link between pest density and damage is also likely to depend on plant growing conditions. Generally, good growing conditions increase plant compensating abilities (Fenemore 1984; Pedigo et al. 1986; Maschinski and Whitham 1989). More specifically, as root-feeding pests induce symptoms similar to those of drought (Gange and Brown 1989; Foggo and Speight 1993), the availability of water may be a crucial factor determining the ability of plants to tolerate a pest attack (Godfrey and Yeargan 1985; Dunn and Frommelt 1998). In the present study, the spring was particularly wet: the meteorological station nearby $(1.6 \mathrm{~km})$ recorded $181.5 \mathrm{~mm}$ throughout the experiment. Such precipitation levels are very unlikely to induce water stress in broccoli: in warmer conditions, Erdem et al. (2010) showed significant water stress only when spring broccoli received as little as $130 \mathrm{~mm}$, but no stress when it received $193 \mathrm{~mm}$ or more. In addition, the windbreak effect of the cages probably limited desiccation. These favorable conditions may partly explain the absence of mortality.

Although the level of $D$. radicum mortality is usually high $(\sim 80-90 \%$; Hughes and Salter 1959; Meyling et al. 2013), it was extreme in our experiment as a hundred percent mortality has never been reported. First, it cannot be ruled out that some pupae were beyond the area covered by the auger used (i.e. $12 \mathrm{~cm}$ in diameter). Following Hughes (1960) and Finch et al. (1978) the area prospected was enough to collect more than $70 \%$ of the pupae. Given that we collected only two pupae within this area, it is unlikely that the pupae missed would have 
substantially changed the estimation of $D$. radicum mortality rate. Then, some mortality occurred during the egg stage: we showed that between 10 and $25 \%$ of the eggs were unviable, which is consistent with previous studies conducted with this biological model (Neveu et al. 1997). Actual egg mortality in the field could have been higher due to one supplementary handling, to deposit the eggs at the base of plant stems. Additional egg mortality could be attributable to predation by ground dwelling arthropods. Indeed, Fig. S1 in Supplementary materials shows that our exclusion setup did not completely suppress the ground dwelling arthropod fauna, at least during the weeks of plant infestation. The carabid family, that dominated this fauna, was essentially represented by two species Metallina lampros and Phyla obtusa. These share functional traits which likely determine the efficiency of ground dwelling predators on D. radicum: small body size and carnivorous diet (Purtauf et al. 2005). Metallina lampros is thought to be specialized on D. radicum and to contribute largely to its natural regulation (Hughes 1959; Coaker and Williams 1963; Andersen et al. 1983).

On the other hand, the results discussed above concerning the decreased plant growth and yield show that at least some of the eggs survived and produced harmful larvae. As almost no pupae were found around broccoli roots, some pest mortality also appears to have occurred during the larval stage. Based on previous studies performed in open fields, predation by ground dwelling arthropods on buried materials (here, $D$. radicum larvae) seems rather unlikely (Finch and Elliott 1994; Lee and Edwards 2012). However, using insect-proof cages meant that any trapped ground dwelling predators had virtually no alternative resources on which to prey besides the $D$. radicum eggs (no other Brassica herbivores were observed inside the cages). We also recorded high numbers of ants at the beginning of May (Fig. S1, in Supplementary materials), i.e. during larval development of the first introduced eggs. Several authors showed that many ant species are significant predators of below ground pests (Carroll and Janzen 1973; Yadav et al. 2012; Pacheco et al. 2017). For instance, Yadav et al. (2012) showed that ants caused $60 \%$ mortality of Galleria mellonella larvae that were being used as below ground sentinel prey. The unusually high mortality recorded here may therefore be related to the unusual presence of ants. Also, as mentioned above, the spring when the study took place was particularly wet and the soil was hydromorphic. High soil moisture is known to decrease larval survival (Finch and Skinner 1988) and could have contributed to the high mortality observed. Finally, the favorable growing conditions in our experiment may have increased the constitutive and induced resistance mechanisms of the plant and caused additional larval mortality. Induction of plant defense following infestation may explain some of the $D$. radicum mortality as well as some of the effects on plant traits, through a trade-off between resistance (i.e. mobilizing energy and matter to produce defensive compounds) and growth, i.e. an allocation cost (Strauss et al. 2002).

\section{Conclusion}

In our experiment, the introduced $D$. radicum suffered high mortality rates, thus we could not establish a clear relationship between pest density and plant mortality. As a systematic insecticide treatment at planting (Spinosad, authorized in conventional and organic production) is currently used to prevent plant mortality, the re-assessment of this relationship is urgently needed. However, we showed that plant mortality is not the only cause of damage in this 
crop/pest system and that sublethal effects can lead to a $40 \%$ decrease in broccoli mass at

396 harvest even in conditions where the survival of the pest is not optimal. Based on our findings

397 concerning pest harmfulness coupled to forecast models of population dynamics (e.g. Collier

398 et al. 1991) it should be possible to develop decision support tools evaluating the relevance of

399 the treatment, based on the expected pest infestation and its expected impact on crops. As

400 predation by ground dwelling arthropods was probably a mortality factor of prime significance

401 in the present study, it may be very valuable to take them into account in such models.

402 Acknowledgements

403 We thank Paul Adam for helpful contribution in data collection, the "Unité Expérimentale de

404 la Motte" (UE 0787) for the setup of the experimental plot and Dr. Leigh Gebbie for the English

405 revision of this manuscript.

\section{Author contribution statement}

407 All authors conceived and designed research. MV, LD and XM performed the field work. XM

408 analyzed data. XM, ALR, AMC, VF and YT were involved in writing of the manuscript.

409 Funding

410 This work was supported by the GIS PIClég (grant $\mathrm{n}^{\circ} \mathrm{P} 00315$ ), the Région Bretagne (grant $\mathrm{n}^{\circ}$

$4110461 / \mathrm{COH} 14000 / 00001042$ ) and the Chaire AEI (grant $\mathrm{n}^{\circ} 2016$ 0190).

412 Conflict of interest

413 The authors declare that they have no conflict of interest.

414 Compliance with ethical standards

415 All applicable international, national, and/or institutional guidelines for the care and use of 416 animals were followed. 
Andersen A, Hansen ÅG, Rydland N, Øyre G (1983) Carabidae and Staphylinidae (Col.) as predators of eggs of the turnip root fly Delia floralis Fallén (Diptera, Anthomyiidae) in cage experiments. J Appl Entomol 95:499-506. doi: 10.1111/j.14390418.1983.tb02673.x

Aubertot J-N, Robin M-H (2013) Injury Profile SIMulator, a qualitative aggregative modelling framework to predict crop injury profile as a function of cropping practices, and the abiotic and biotic environment. I. Conceptual bases. PLOS ONE 8:e73202. doi: 10.1371/journal.pone.0073202

Bates D, Mächler M, Bolker B, Walker S (2015) Fitting linear mixed-effects models using lme4. J Stat Softw 67:1-48. doi: 10.18637/jss.v067.i01

Bligaard J (1999) Damage thresholds for cabbage root fly [Delia radicum (L.)] in cauliflower assessed from pot experiments. Acta Agric Scand Sect B — Soil Plant Sci 49:57-64. doi: 10.1080/09064719950135713

Bligaard J, Meadow R, Nielsen O, Percy-Smith A (1999) Evaluation of felt traps to estimate egg numbers of cabbage root fly, Delia radicum, and turnip root fly, Delia floralis in commercial crops. Entomol Exp Appl 90:141-148. doi: 10.1046/j.15707458.1999.00432.x

Boica Junior AL, Costa EN, Sardinha de Souza BH, et al (2015) Antixenosis and tolerance to Diabrotica speciosa (Coleoptera: Chrysomelidae) in common bean cultivars. Fla Entomol 98:464-472. doi: 10.1653/024.098.0212

Brandelero FD, Brum B, Storck L, et al (2016) Plant characters of broccoli determinants of head production. Cienc Rural 46:963-969. doi: 10.1590/0103-8478cr20150750

Cardona C, Gonzalez R, Schoonhoven AV (1982) Evaluation of damage to common beans by larvae and adults of Diabrotica balteata and Cerotoma facialis. J Econ Entomol 75:324-327. doi: 10.1093/jee/75.2.324

Cargnelutti Filho A, Toebe M, Alves BM, et al (2015) Leaf area estimation of canola by leaf dimensions. Bragantia 74:139-148. doi: 10.1590/1678-4499.0388

Carroll CR, Janzen DH (1973) Ecology of foraging by ants. Annu Rev Ecol Syst 4:231-257. doi: 10.1146/annurev.es.04.110173.001311

Coaker TH, Williams DA (1963) The importance of some Carabidae and Staphylinidae as predators of the cabbage root fly, Erioischia Brassicae (Bouché). Entomol Exp Appl 6:156-164. doi: 10.1111/j.1570-7458.1963.tb00613.x

Collier RH, Finch S, Phelps K (1991) A simulation model for forecasting the timing of attacks of Delia radicum on cruciferous crops. EPPO Bull 21:419-424. doi: 10.1111/j.13652338.1991.tb01271.x

Desneux N, Decourtye A, Delpuech J-M (2007) The sublethal effects of pesticides on beneficial arthropods. Annu Rev Entomol 52:81-106. doi: 10.1146/annurev.ento.52.110405.091440

Devictor V, Clavel J, Julliard R, et al (2010) Defining and measuring ecological specialization. J Appl Ecol 47:15-25. doi: 10.1111/j.1365-2664.2009.01744.x

Dosdall LM, Herbut MJ, Cowle NT (1994) Susceptibilities of species and cultivars and canola and mustard to infestation by root maggots (Delia spp.) (Diptera, Anthomyiidae). Can Entomol 126:251-260 
Dufault RJ (1997) Determining heat unit requirements for broccoli harvest in coastal south carolina. J Am Soc Hortic Sci 122:169-174

Dunn JP, Frommelt K (1998) Effects of below-ground herbivory by Diabrotica virgifera virgifera (Col., Chrysomelidea) and soil moisture on leaf gas exchange of maize. J Appl Entomol 122:179-183. doi: 10.1111/j.1439-0418.1998.tb01481.x

Eilenberg J, Hajek A, Lomer C (2001) Suggestions for unifying the terminology in biological control. BioControl 46:387-400. doi: 10.1023/A:1014193329979

El Titi A (1977) Determination of the economic threshold of the cabbage root fly (Erioischia brassicae Bouché) in early cauliflower. I. The relationship between population density of the fly, chemical control and yield. Z Pflanzenkrankh Pflanzenschutz 84:65-77

El Titi A (1979) Further experiments on the determination of the economic threshold of the cabbage root fly (Erioischia brassicae Bouché) in early cauliflower. Z Pflanzenkrankh Pflanzenschutz 86:65-74

Erdem Y, Arin L, Erdem T, et al (2010) Crop water stress index for assessing irrigation scheduling of drip irrigated broccoli (Brassica oleracea L. var. italica). Agric Water Manag 98:148-156. doi: 10.1016/j.agwat.2010.08.013

Estorgues V (2005) Maladies et ravageurs des légumes de plein champ en Bretagne. Chambres d'agriculture de Bretagne

Faraway JJ (2006) Extending the linear model with R : generalized linear, mixed effects and non parametric regression models. Chapman \& Hall/CRC Taylor \& Francis group

Feller C, Bleiholder H, Buhr L, et al (1995) Phänologische Entwicklungsstadien von Gemüsepflanzen. II. Fruchtgemüse und Hülsenfrüchte. Nachrichtenblatt Dtsch Pflanzenschutzdienste 47:193-206

Fenemore PG (1984) Plant Pests and Their Control. Elsevier, United Kingdom

Finch S, Elliott MS (1994) Predation of cabbage root fly eggs and larvae by carabid ground beetles - fact or fantasy? IOBC-WPRS Bull 17:109-114

Finch S, Skinner G (1988) Mortality of the immature stages of the cabbage root fly. In: Proceedings of the CEC / IOBC experts'group meeting. Cavalloro R. \& Pellerents C., Rennes, pp 45-48

Finch S, Skinner G, Freeman GH (1978) Distribution and analysis of cabbage root fly pupal populations. Ann Appl Biol 88:351-356

Foggo A, Speight MR (1993) Root damage and water stress: treatments affecting the exploitation of the buds of common ash Fraxinus excelsior L., by larvae of the ash bud moth Prays fraxinella Bjerk. (Lep., Yponomeutidae). Oecologia 96:134-138. doi: 10.1007/BF00318041

Fowler NL, Rausher MD (1985) Joint effects of competitors and herbivores on growth and reproduction in Aristolochia reticulata. Ecology 66:1580-1587. doi: 10.2307/1938020

Fox J, Weisberg S (2011) An R companion to applied regression, 2nd edn. Sage, Thousand Oaks (CA)

Gange AC, Brown VK (1989) Effects of root herbivory by an insect on a foliar-feeding species, mediated through changes in the host plant. Oecologia 81:38-42. doi: 10.1007/BF00377007 
Geiger F, Bengtsson J, Berendse F, et al (2010) Persistent negative effects of pesticides on biodiversity and biological control potential on European farmland. Basic Appl Ecol 11:97-105. doi: 10.1016/j.baae.2009.12.001

Godfrey LD, Yeargan KV (1985) Influence of soil moisture and weed density on clover root curculio, Sitona hispidulus, larval stress to alfalfa. J Agric Entomol 2:370-377

Grevsen K (2000) Modelling plant development of broccoli. Acta Hortic 533:567-574. doi: 10.17660/ActaHortic.2000.533.71

Heichel GH, Turner NC (1983) $\mathrm{CO}_{2}$ assimilation of primary and regrowth foliage of red maple (Acer rubrum L.) and red oak (Quercus rubra L.): response to defoliation. Oecologia 57:14-19. doi: 10.1007/BF00379555

Hopkins RJ, Birch ANE, Griffiths DW, et al (1995) Changes in the dry matter, sugar, plant fibre and lignin contents of swede, rape and kale roots in response to turnip root fly (Delia floralis) larval damage. J Sci Food Agric 69:321-328. doi: 10.1002/jsfa.2740690308

Hughes RD (1960) A method of estimating the numbers of cabbage root fly pupae in the soil. Plant Pathol 9:15-17

Hughes RD (1959) The natural mortality of Erioischia brassicae (Bouché) (Diptera, Anthomyiidae) during the egg stage of the first generation. J Anim Ecol 28:343-357

Hughes RD, Salter DD (1959) Natural mortality of Erioischia brassicae (Bouché) (Diptera, Anthomyiidae) during the immature stages of the first generation. J Anim Ecol 28:231241

Hunter MD (2001) Out of sight, out of mind: the impacts of root-feeding insects in natural and managed systems. Agric For Entomol 3:3-9. doi: 10.1046/j.1461-9563.2001.00083.x

International conference on global crop losses (2017) Synthesis and report. INRA, Paris

IUSS working group WRB (2015) World reference base for soil resources 2014, update 2015 International soil classification system for naming soils and creating legends for soil maps. FAO, Rome

Josso C, Le Ralec A, Raymond L, et al (2013) Effects of field and landscape variables on crop colonization and biological control of the cabbage root fly Delia radicum. Landsc Ecol 28:1697-1715. doi: 10.1007/s10980-013-9928-3

Karban R, Courtney S (1987) Intraspecific host plant choice: lack of consequences for Streptanthus tortuosus (Cruciferae) and Euchloe hyantis (Lepidoptera: Pieridae). Oikos 48:243-248. doi: 10.2307/3565508

Kloen H, Altieri MA (1990) Effect of mustard (Brassica hirta) as a non-crop plant on competition and insect pests in broccoli (Brassica oleracea). Crop Prot 9:90-96. doi: 10.1016/0261-2194(90)90084-K

Lamy F, Dugravot S, Cortesero AM, et al (2017) One more step toward a push-pull strategy combining both a trap crop and plant volatile organic compounds against the cabbage root fly Delia radicum. Environ Sci Pollut Res 1-12. doi: 10.1007/s11356-017-9483-6

Lee JC, Edwards DL (2012) Impact of predatory carabids on below- and above-ground pests and yield in strawberry. BioControl 57:515-522. doi: 10.1007/s10526-011-9425-Z

Lenth RV (2017) emmeans: Estimated Marginal Means, aka Least-Squares Means

Lindemann-Zutz K, Fricke A, Stützel H (2016) Prediction of time to harvest and its variability in broccoli (Brassica oleracea var. italica) Part I. Plant developmental variation and 
forecast of time to head induction. Sci Hortic 198:424-433. doi: 10.1016/j.scienta.2015.12.023

Maschinski J, Whitham TG (1989) The continuum of plant responses to herbivory: the influence of plant association, nutrient availability, and timing. Am Nat 134:1-19. doi: $10.1086 / 284962$

Meyling NV, Navntoft S, Philipsen H, et al (2013) Natural regulation of Delia radicum in organic cabbage production. Agric Ecosyst Environ 164:183-189. doi: 10.1016/j.agee.2012.09.019

Murray PJ, Hatch DJ, Cliquet JB (1996) Impact of insect root herbivory on the growth and nitrogen and carbon contents of white clover (Trifolium repens) seedlings. Can J Bot 74:1591-1595. doi: 10.1139/b96-192

Neveu N, Langlet X, Brunel E, et al (1997) The fine structure of the egg shells of the cabbage maggot, Delia radicum L. (Diptera: Anthomyiidae) and its relation with developmental conditions and oviposition site. Can J Zool 75:535-541

Oerke E-C (2006) Crop losses to pests. J Agric Sci 144:31-43. doi: $10.1017 / \mathrm{S} 0021859605005708$

Olfati JA, Peyvast G, Shabani H, Nosratie-Rad Z (2010) An estimation of individual leaf area in cabbage and broccoli using non-destructive methods. J Agric Sci Technol 12:627632

Pacheco R, Camacho GP, Frizzo TLM, Vasconcelos HL (2017) Effects of land-use changes on ecosystem services: decrease in ant predation in human-dominated landscapes in central Brazil. Entomol Exp Appl 162:302-308. doi: 10.1111/eea.12542

Pedigo LP, Hutchins SH, Higley LG (1986) Economic injury levels in theory and practice. Annu Rev Entomol 31:341-368. doi: 10.1146/annurev.en.31.010186.002013

Poston FL, Pedigo LP, Welch SM (1983) Economic injury levels: reality and practicality. Bull Entomol Soc Am 29:49-53. doi: 10.1093/besa/29.1.49

Purtauf T, Dauber J, Wolters V (2005) The response of carabids to landscape simplification differs between trophic groups. Oecologia 142:458-464. doi: 10.1007/s00442-004$1740-\mathrm{y}$

R core team (2017) R: a language and environment for statistical computing. $R$ foundation for statistical computing, Vienna, Austria

Rogers DJ, Brier HB (2010) Pest-damage relationships for Helicoverpa armigera (Hübner) (Lepidoptera: Noctuidae) on vegetative soybean. Crop Prot 29:39-46. doi: 10.1016/j.cropro.2009.08.016

Rosenheim JA, Wilhoit LR, Goodell PB, et al (1997) Plant compensation, natural biological control, and herbivory by Aphis gossypii on pre-reproductive cotton: the anatomy of a non-pest. Entomol Exp Appl 85:45-63. doi: 10.1046/j.1570-7458.1997.00233.x

Strauss SY, Agrawal AA (1999) The ecology and evolution of plant tolerance to herbivory. Trends Ecol Evol 14:179-185. doi: 10.1016/S0169-5347(98)01576-6

Strauss SY, Rudgers JA, Lau JA, Irwin RE (2002) Direct and ecological costs of resistance to herbivory. Trends Ecol Evol 17:278-285. doi: 10.1016/S0169-5347(02)02483-7

Tartaglia F de L, Righi EZ, da Rocha L, et al (2016) Non-destructive models for leaf area determination in canola. Rev Bras Eng Agric E Ambient 20:551-556. doi: 10.1590/1807-1929/agriambi.v20n6p551-556 
604

605

606

607
Teixeira MLF, Coutinho LCH, Franco AA (1996) Effects of Cerotoma arcuata (Coleoptera: Chrysomelidae) on predation of nodules and on $\mathrm{N}_{2}$ fixation of Phaseolus vulgaris. $\mathrm{J}$ Econ Entomol 89:165-169. doi: 10.1093/jee/89.1.165

Turnock W, Timlick B, Galka B, Palaniswamy P (1992) Root maggot damage to canola and the distribution of Delia spp. (Diptera, Anthomyiidae) in Manitoba. Can Entomol 124:49-58

Verdugo JA, Francis F, Ramirez CC (2016) A review on the complexity of insect-plant interactions under varying levels of resources and host resistance: the case of Myzus persicae-Prunus persica. Biotechnol Agron Soc Environ 20:533-541

Yadav P, Duckworth K, Grewal PS (2012) Habitat structure influences below ground biocontrol services: A comparison between urban gardens and vacant lots. Landsc Urban Plan 104:238-244. doi: 10.1016/j.landurbplan.2011.10.018

Zadoks JC (1985) On the conceptual basis of crop loss assessment: the threshold theory. Annu Rev Phytopathol 23:455-473. doi: 10.1146/annurev.py.23.090185.002323 
608 Table 1 Pattern of artificial infestation of the broccoli plants with cabbage root fly eggs

609

\begin{tabular}{ccccccccccc}
\hline $\begin{array}{c}1^{\text {st }} \text { infestation } \\
(3 \text { weeks after planting) } \\
2^{\text {nd } \text { infestation }}\end{array}$ & 0 & 1 & 3 & 6 & 9 & 12 & 15 & 18 & 24 & 30 \\
$\begin{array}{c}(4 \text { weeks after planting) } \\
3^{\text {rd } \text { infestation }}\end{array}$ & 0 & 3 & 4 & 8 & 12 & 16 & 20 & 24 & 32 & 40 \\
\hline 5 weeks after planting $)$ & 0 & 1 & 3 & 6 & 9 & 12 & 15 & 18 & 24 & 30 \\
\hline Total & 0 & 5 & 10 & 20 & 30 & 40 & 50 & 60 & 80 & 100 \\
\hline
\end{tabular}

610

611 Table 2 Effect of the number of D. radicum eggs deposited per plant and its interaction with 612 the date of measurement on the development and growth traits recorded for the broccoli plants. 613 Bold p-values show significant differences at $\alpha=5 \%$

614

\begin{tabular}{|c|c|c|c|c|c|c|c|}
\hline & \multicolumn{4}{|c|}{ Number of eggs } & \multicolumn{3}{|c|}{$\begin{array}{c}\text { Interaction "number of } \\
\text { eggs: date" }\end{array}$} \\
\hline & $\chi^{2}$ & $\mathrm{DF}$ & P-val & Trend & $\chi^{2}$ & DF & P-val \\
\hline Number of leaves & 6.61 & 1 & 0.010 & $\searrow$ & 15.17 & 9 & 0.086 \\
\hline $\begin{array}{l}\text { Proportion of plants with } \\
\text { at least one lateral shoot }\end{array}$ & 2.36 & 1 & 0.125 & & 8.64 & 5 & 0.124 \\
\hline $\begin{array}{l}\text { Proportion of plants with } \\
\text { a visible inflorescence }\end{array}$ & 8.25 & 1 & 0.004 & $\searrow$ & 2.34 & 1 & 0.126 \\
\hline Relative largest leaf area & 13.66 & 1 & $<0.001$ & $\searrow$ & 24.16 & 8 & 0.002 \\
\hline $\begin{array}{l}\text { Height above ground of } \\
\text { the apical meristem }\end{array}$ & 5.09 & 1 & 0.024 & $\searrow$ & 54.82 & 8 & $<0.001$ \\
\hline
\end{tabular}


616 Fig. 1 Evolution through time of the linear trend between plant traits (a: number of leaves; $b$ :

617 proportion of plants with at least one lateral shoot; c: proportion of plants with an inflorescence;

$618 \mathrm{~d}$ : height above ground of the apical meristem in $\mathrm{cm}$ and e: relative largest leaf area in $\mathrm{cm}^{2}$ ) and

619 the number of eggs deposited. Each point and associated error bar represents the estimate \pm

$62095 \%$ confidence interval of this trend, obtained with function 'emtrends' (Lenth 2017). A

621 negative value indicates that plant development or growth is negatively correlated with the

622 number of eggs deposited at the time of measurement. The trend is significant (i.e. the effect of

623 the number of eggs on plant trait is significant at a given time) if the error bar does not cross

624 the horizontal dashed line in 0 . Vertical dotted lines represent the three artificial infestations of

625 broccoli plants

626

627 Fig. 2 Plant development (a: leaf number, mean \pm SE; b: proportion of plants with at least one 628 lateral shoot, prop \pm SE and c: proportion of plants with a visible inflorescence, prop $\pm S E$ ) and 629 growth traits (d: height above ground of the apical meristem in $\mathrm{cm}$, mean $\pm \mathrm{SE}$; e: relative 630 largest leaf area in $\mathrm{cm}^{2}$, mean $\pm \mathrm{SE}$ ) as a function of the number of $D$. radicum eggs deposited 631 per plant for the measurement date indicated above the graphs, corresponding to the time when 632 the correlation between plant trait and egg density was the most negative (Fig. 1). The dashed 633 grey lines present the regression curves obtained with the coefficients of the models presented 634 in the text and in Table 2

636 Fig. 3 Proportion of plants showing root injuries (prop \pm SE; a) and broccoli mass at harvest (in 637 grams, mean $\pm \mathrm{SE}$; b) according to the number of $D$. radicum eggs deposited per plant 


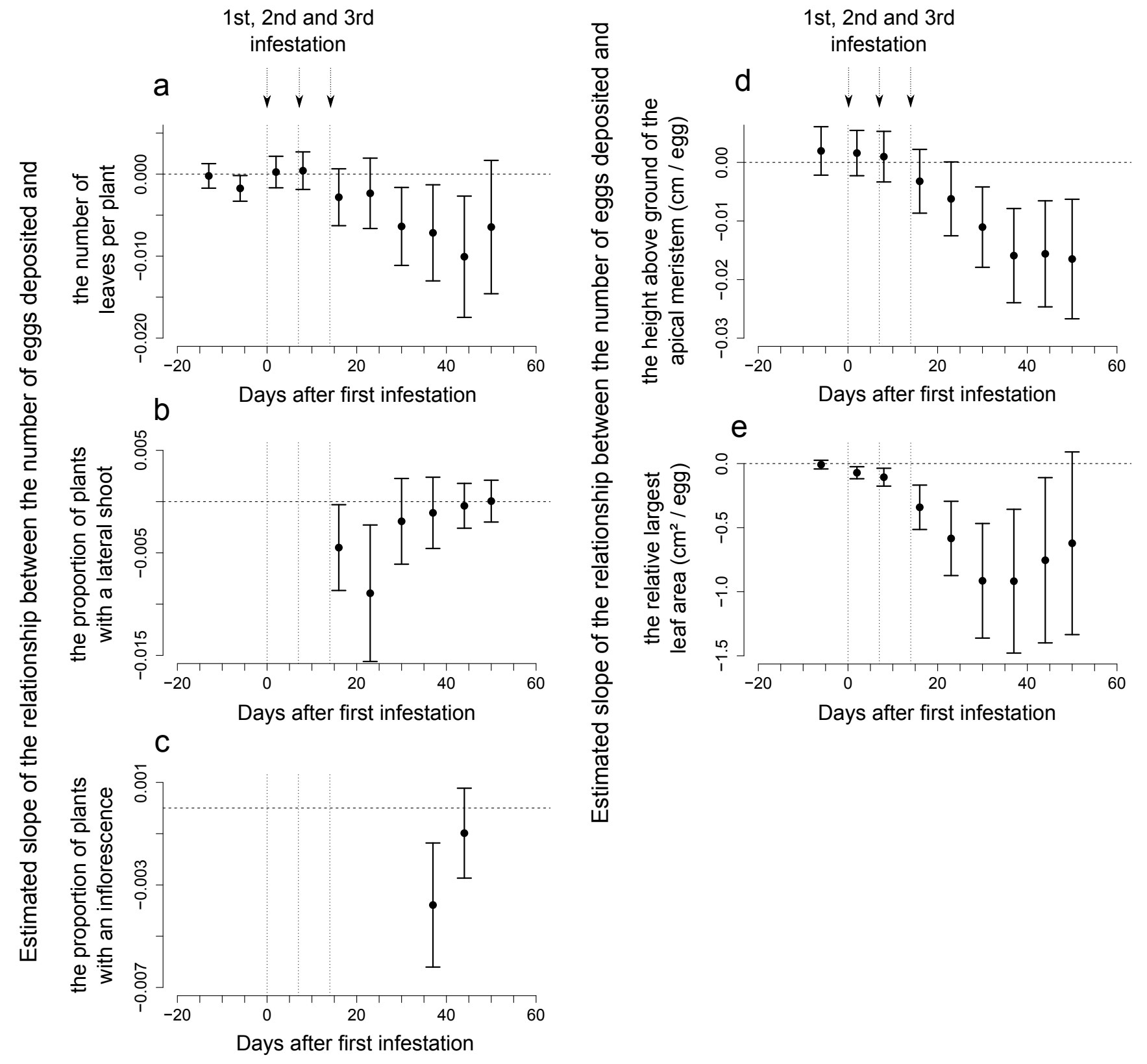


a

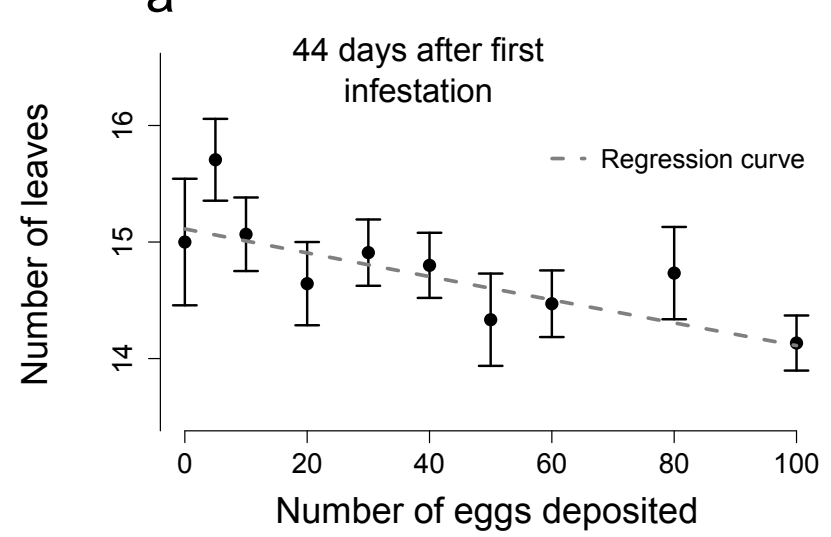

b

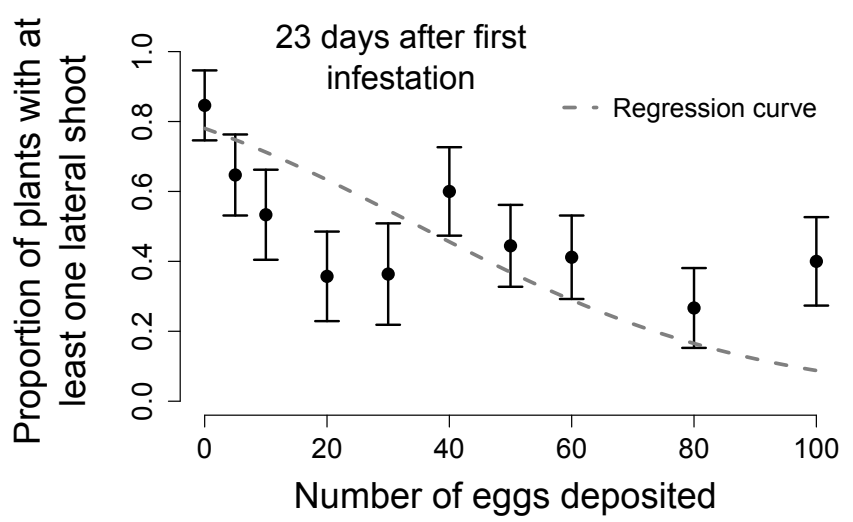

C

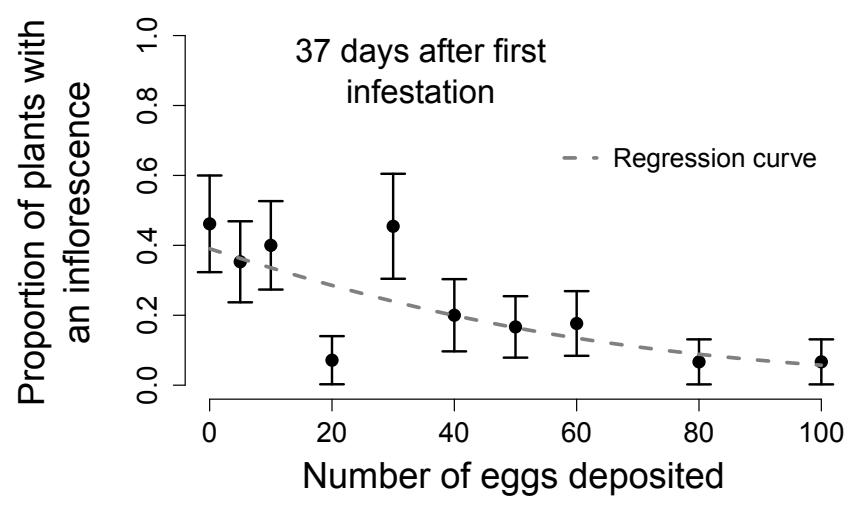

d

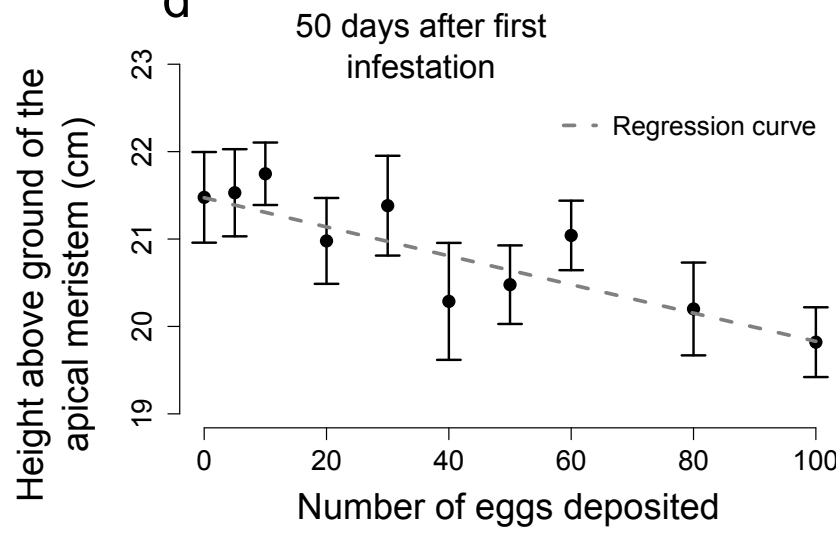

e

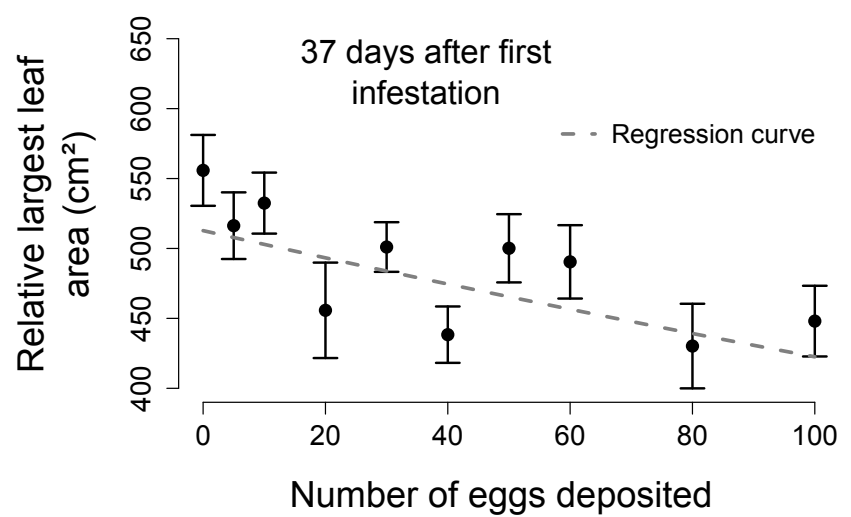


a

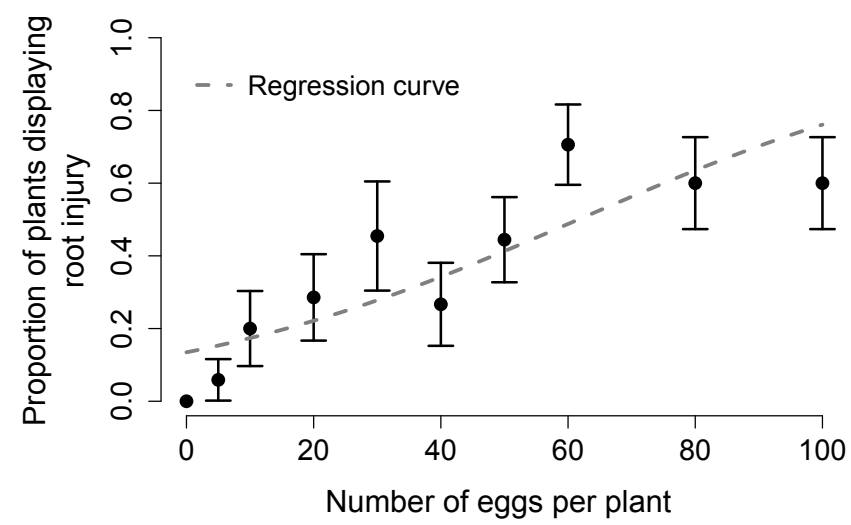

b

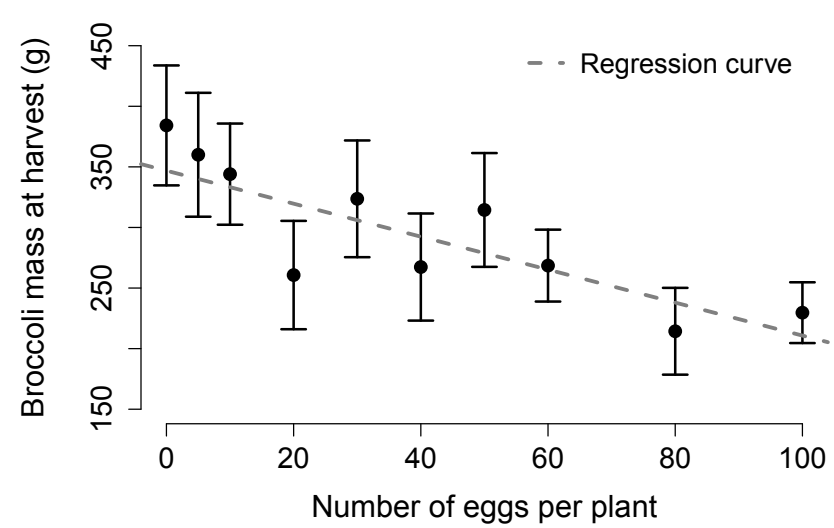

